\title{
АНАЛИЗ КАДРОВОГО ПОТЕНЦИАЛА ИРКУТСКОЙ ОБЛАСТИ И ОСОБЕННОСТИ ПРОЯВЛЕНИЯ ИНЕРЦИОННОСТИ НА РЕГИОНАЛЬНОМ РЫНКЕ ТРУДА
}

\begin{abstract}
АНнОтАЦИЯ. Развитие экономики определяется интенсивностью инвестиционных процессов в ней. Одной из главных категорий инвестиций является инвестиционный потенциал, который способствует модернизации экономики. Однако модернизация невозможна без квалифицированных кадров и специалистов. В связи с этим анализ и прогнозирование развития рынка труда являются необходимыми мероприятиями, способствующими экономическому развитию, но объективный прогноз, способствующий принятию эффективных управленческих решений, требует учета фактора инерционности. В статье проводится анализ кадрового потенциала Иркутской области, рассматриваются и выявляются основные признаки проявления инерционности в развитии отношений на региональном рынке труда. Предлагаются мероприятия по повышению кадрового потенциала области, а также с учетом фактора инерционности определяется период реализации данных мероприятий и время выхода на новый качественный уровень развития системы. При этом период времени реализации предложенных направлений по повышению кадрового потенциала характеризует преломление инерции, а время выхода на новый качественный уровень развития системы - временной период до наступления следующей экономической фазы, характеризующейся получением результата от внедрения мероприятий.

кЛючЕВЫЕ СЛОВА. Инерционность; кадровый потенциал; инвестиционный потенциал; рынок труда; институциональная инерция; время; экономические фазы; прерывание инерционного процесса; устойчивость; изменчивость.

ИНФОРМАЦИЯ О СТАТЬЕ. Дата поступления 24 декабря 2015 г.; дата принятия к печати 25 января 2016 г.; дата онлайн-размещения 23 марта 2016 г.
\end{abstract}

I. Yu. Novikova Baikal State University, Irkutsk, Russian Federation

\section{ANALYSIS OF PERSONNEL POTENTIAL OF IRKUTSK OBLAST AND FEATURES OF INERTIA MANIFESTATION ON THE REGIONAL LABOR MARKET}

\begin{abstract}
Development of economy is determined by intensity of investment processes in it. One of the main categories of investment is the investment potential which contributes to economic modernization. However, modernization is impossible without qualified personnel and specialist. In this context, analysis and forecast of the labor market development are essential activities that contribute to economic development, but objective forecast that promotes adopting effective management decisions requires consideration of the inertia factor. The article carries out an analysis of personnel potential of Irkutsk Oblast, considers and identifies essential features of inertia manifestation in developing relations at the regional labor market. It offers measures for improving the Oblast's personnel potential, as well as, in view of the inertia factor, specifies the period for the implementing these action items and the moment of transition to a new qualitative level of the system development. At that, the implementation period for the proposed directions for increasing the personnel potential characterizes the turning point of the inertia, while the time of stepping out on a new qualitative level of the system development is a temporary period before oncoming the next economic phase characterized by obtaining results from introducing these actions items.
\end{abstract}

(C) И. Ю. Новикова, 2016

\section{Baikal Research Journal}


KEYWORDS. Inertia; personnel potential; investment potential; labor market; institutional inertia; time; economic phases; interruption of inertial process; sustainability; volatility.

ARTICLE INFO. Received December 25, 2015; accepted January 25, 2016; available online March 23, 2016.

Прогнозирование разнообразных социально-экономических процессов невозможно без познания сущности экономической инерционности, которая позволяет выявить и объяснить многие закономерности экономической динамики, что особенно значимо в период нестабильности. Сущность фактора инерционности проявляется в изменчивости и устойчивости и предстает как устойчивое сохранение определенных изменений [1]. Изменчивость играет ведущую роль в развитии экономики. Качественное развитие экономической системы означает, прежде всего, появление нового, а также изменение взаимосвязей и свойств ее элементов. Устойчивость, в свою очередь, - форма фиксации достигнутого результата в развитии системы [2, с. 87].

Инерционность целесообразно рассматривать как механизм связи прошлого с настоящим, формирование будущего посредством устойчивого соотношения традиционного и инновационного [3, c. 310]. Показатель инерционности характерен для любой отрасли, но его величина может существенно варьироваться, однако наибольшая интенсивность инерционных процессов прослеживается в инвестиционных отраслях.

Одной из главных категорий инвестиций является категория «инвестиционный потенциал», которая напрямую влияет на инвестиционный климат [4, с. 9]. В структуре инвестиционного потенциала любого хозяйствующего субъекта особое значение имеет кадровый потенциал, как производная трудового потенциала, который, в свою очередь, является производной человеческого потенциала.

Фактор инерционности при рассмотрении кадрового потенциала следует учитывать в русле институционального подхода. В данном случае для перехода на новый качественный уровень развития необходимы преобразования общественных институтов, механизмов взаимодействия субъектов, психологии людей и т. д. По словам А. Маршалла: «Социально-экономические системы инерционны, изменения в них не идут слишком быстро, так как главный элемент социально-экономической системы - человек, а люди консервативны, мало склонны менять свои привычные принципы поведения» ${ }^{1}$. Таким образом, инерция институтов, их внутренняя изменчивость и инерционность, разная степень инерционности формальных и неформальных институтов оказывают значительное влияние на экономическое развитие хозяйствующего субъекта [5, с. 211].

Различные меры по усилению критического отношения к прежней институциональной системе не гарантируют быстрого перехода к системе норм, способствующих развитию экономической системы, изменению ее структуры [6, с. 152]. Формальные правила под воздействием накопленной институциональной традиции наполняются принципиально новым содержанием - происходит процесс, названный «деформализацией норм». Однако одновременно импорт институтов служит важным толчком для эволюции норм и правил, фактически определяющих поведение участников трансакций, но вместо ускорения социально-экономического развития возможен противоположный эффект [7, с. 62].

Доверие к новому институту - своего рода индикатор спроса на него, преодоление институциональной инерции. Чем ниже массовое доверие к новому институту, тем выше расходы по внедрению и поддержке его существования, тем значительнее трансакционные издержки его использования. Доверие к экономическим институ-

${ }^{1}$ URL : http://ecsocman.hse.ru/data/927/687/1219/Glava_2._586_KB.pdf.

\section{Baikal Research Journal}

электронный научный журнал Байкальского государственного университета 
там, к экономическим партнерам - важные неформальные институты, действующие на всех уровнях экономики, влияние и инерционность которых необходимо учитывать в процессе реформирования институциональной системы [8, с. 73$]$.

Влияние институциональной инерции на экономическое развитие хозяйствующего субъекта можно проследить, проанализировав и оценив кадровый потенциал Иркутской области, который в современных условиях приобретает определяющее значение.

Проблема определения потребности экономики в кадрах (по уровням подготовки и группам специальностей) является одной из наиболее сложных и актуальных исследовательских и практических проблем. Подходы к определению потребности в кадрах в России развиваются давно. В середине 1980-х гг. планирование подготовки кадров специалистов рассматривалось как интеграционный процесс, включающий ряд этапов. Потребность в кадрах специалистов определялась на основе прогноза развития отраслей производственной и непроизводственной сфер, а также прогноза занятости населения. Одной из конечных целей подобных прогнозов была разработка концепции развития системы высшего образования [9, с. 106].

Развитие научно-исследовательской базы хозяйствующих субъектов и внедрение инновационных технологий приводят к изменению профессионально-квалификационной структуры кадров. Для обоснованной диагностики трудовой комфортности недостаточно оценивать только варианты реакции персонала на изменения. Следует учитывать, как минимум, еще два основополагающих фактора: профессиональную подготовленность к работе в новых условиях (наличие «профессионального ядра») и уровень информированности персонала о целях и задачах преобразований [10, с. 24].

Модернизация производства ведет к увеличению спроса на квалифицированных специалистов и повышению требований работодателей к качеству подготовки работников. При этом численность учащихся, подготавливаемых образовательными организациями, реализующими программы среднего профессионального образования, продолжает снижаться. Спрос на квалифицированных рабочих и специалистов остается неудовлетворенным и продолжает увеличиваться.

За период с 2006 по 2014 г. произошло сокращение количества выпускников образовательных организаций, реализующих программы среднего профессионального образования за 2006-2014 гг. ${ }^{2}$ Снижение уровня привлекательности производства и престижа рабочих профессий, ориентация молодежи на получение высшего образования ${ }^{3}$ продолжает оказывать существенное давление на систему среднего профессионального образования (табл.). Вместе с тем, потребность в подготовке квалифицированных рабочих остается не удовлетворенной. Так, в структуре подготовки специалистов с высшим образованием наибольший удельный вес занимает группа специальностей «экономика и управление» .

\section{Показатели выпуска специалистов \\ государственных образовательных учреждений по уровням образования за 2006-2014 г2. (на начало учебного года), чел.}

\begin{tabular}{|c|c|c|c|c|c|c|c|c|c|}
\hline Уровень образования & 2006 & 2007 & 2008 & 2009 & 2010 & 2011 & 2012 & 2013 & 2014 \\
\hline Среднее профессиональное & 10178 & 10052 & 10030 & 9473 & 8978 & 7890 & 7366 & 7692 & 8200 \\
\hline Высшее профессиональное & 21147 & 23304 & 24025 & 25677 & 27227 & 24708 & 24590 & 23200 & 20076 \\
\hline
\end{tabular}

\footnotetext{
${ }^{2}$ Концепция развития кадрового потенциала Иркутской области на период до 2020 года : утв. распоряжением Правительства Иркут. обл. от 31 марта 2014 г. № 239-рп. Гл. 3 // СПС «КонсультантПлюс» .

3 Регионы России: Высшее профессиональное образование, 2005-2013. URL : http://knoema. com/otoqvfb.
}

\section{Baikal Research Journal}


Таким образом, образовательные организации не в полной мере удовлетворяют спрос работодателей. Это связано как с общим дефицитом кадров по отдельным профессиям, так и с недостаточным практическим опытом работы у выпускников образовательных организаций и несоответствием, в ряде случаев, квалификации выпускников требованиям работодателей.

По данным органов занятости, на региональном рынке труда Иркутской области по состоянию на 1 сентября 2015 г. ${ }^{4}$ спросом пользуются специалисты, имеющие среднее профессиональное образование (рис. 1).

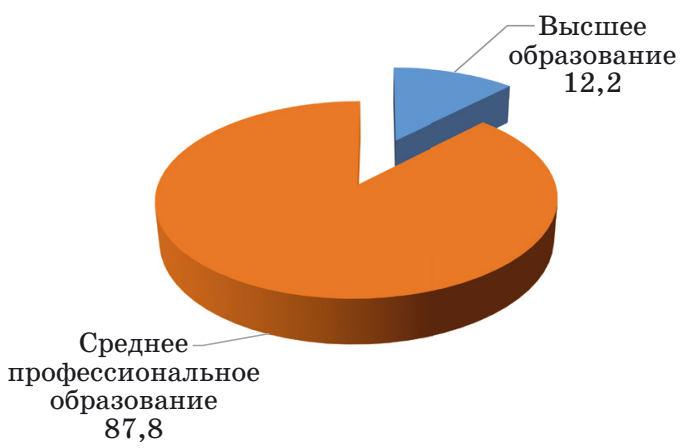

Рис. 1. Структура спроса на работников на региональном рынке труда Иркутской области по уровням образования, \%

Однако начиная с 2013 г. наметилась тенденция восстановления баланса трудовых ресурсов региона. Динамика значений показателей структуры численности выпускников по уровням образования показывает сокращение количества выпуска специалистов образовательных учреждений, реализующих программы высшего профессионального образования и увеличение выпуска специалистов образовательных учреждений, реализующих программы среднего профессионального образования (рис. 2).

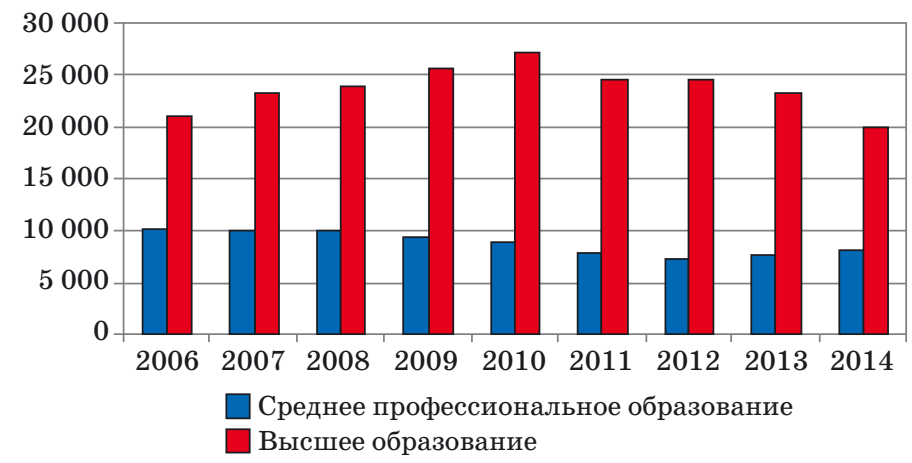

Рис. 2. Динамика показателей структуры численности выпускников в регионе по уровням образования за 2006-2014 г2., чел.

Главный фактор, который необходимо учитывать при прогнозировании ситуации на рынке труда, - время. Баланс спроса и предложения рабочей силы может быть достигнут по истечению определенного временного периода. Данный факт сви-

${ }^{4}$ Прогноз кадровых потребностей экономики Иркутской области на основе потребностей инвесторов и прогноза социально-экономического развития региона / М-во труда и занятости Иркутской области. URL : http://irkzan.ru/home/ministerstvodeyatel/rinok/prognoz-potrebnostivkadrakh.aspx.

\section{Baikal Research Journal}


детельствует о присущей рынку труда инерционности. Чем сложнее устроена экономическая система, тем большую инерцию она имеет.

Инерционность на рынке труда существенно влияет на экономическое развитие региона. Среднее профессиональное образование может быть получено за 3 года (по некоторым специальностям - за 2 года). При этом в колледже обязательно наличие обучения также и по программам углубленной подготовки (4 года). Срок обучения для получения высшего образования в зависимости от формы обучения, страны, системы и профиля колеблется от 4 до 9 лет.

На данный момент в регионе осуществляются различные инвестиционные проекты, которые требуют наличия соответствующих кадров для дальнейшей их реализации. Однако достижение результата на региональном рынке труда, перехода на новый качественный уровень экономического развития возможны по истечению указанных сроков. Исходя из перечисленного, следует сделать вывод, что точкой отсчета указанных сроков для перехода на новый экономический уровень развития региона на рынке труда, преломления инерции экономической системы можно считать период времени получения среднего образования учащимися 9-х и 11 -х классов и поступления их в образовательные учреждения.

Анализ «раскручивания» экономических циклов приводит к появлению либо прерыванию инерционных процессов - одна фаза экономического цикла может создать условия для перехода к другой фазе и т. д. [11, с. 9]. Таким образом, анализ динамики значений показателей структуры численности выпускников в регионе по уровням образования за 2006-2014 гг. показывает, что фазы экономических циклов в 2008 и 2011 г. сделали возможным условия для перехода к другой фазе в 2013 г. Следствием перехода на иной уровень качественного развития стало сокращение разрыва выпускников высшего профессионального образования и выпускников образовательных учреждений, реализующих программы среднего профессионального образования. Данный факт свидетельствует о положительной тенденции развития на рынке труда, ведущей к балансу спроса и предложения рабочей силы в регионе.

Тем не менее, в настоящее время только треть учащихся общеобразовательных организаций ориентируются при выборе будущей профессии на критерий реального спроса на региональном рынке труда. Например, потребность в специалистах направлений «экономика и управление» не значительна, слабо выражена и наблюдается в отдаленных территориях и сельской местности. Однако выпуск студентов образовательных организаций высшего образования Иркутской области резко сдвинут (более 50 \% выпуска) в указанную сферу, а также лидирует направление «юриспруденция» .

Эта тенденция наблюдается на протяжении длительного периода и создает все больший дисбаланс спроса и предложения на рынке труда Иркутской области. В соответствии с данным фактом, а также учитывая прогноз потребностей в кадрах на период до 2027 г., прогнозируется сохранение дисбаланса спроса и предложения на рынке труда.

Большинство востребованных у работодателей Иркутской области профессий и специальностей не пользуются высокой популярностью среди молодежи. Одним из основных мотивов при выборе молодежью будущей профессии является уровень заработной платы, а не возможность трудоустройства в будущем.

По данным Иркутскстата, среднемесячная заработная плата работников Иркутской области за январь-октябрь 2015 г. составила 31863,6 р., что на 4,3\% выше, чем за аналогичный период 2014 г. ${ }^{5}$ Среднемесячная заработная плата работников Иркутской области за январь-октябрь 2015 г. на 3,7\% ниже, чем в среднем по Рос-

${ }^{5}$ Встреча с заместителями глав муниципальных образований Иркутской области. URL : http:// irkzan.ru/App_Shared/WebParts/DataViewers/PopupDocument.aspx?docid=704df8d5-d934-47a9-b30d$47 \mathrm{bb} 4 \mathrm{ec} 973 \mathrm{~d} 1$.

\section{Baikal Research Journal}


сийской Федерации (33 104 р. - по предварительным данным). На рис. 3 представлены темпы прироста заработной платы работников Иркутской области по видам экономической деятельности за январь-октябрь 2015 г. ${ }^{6}$

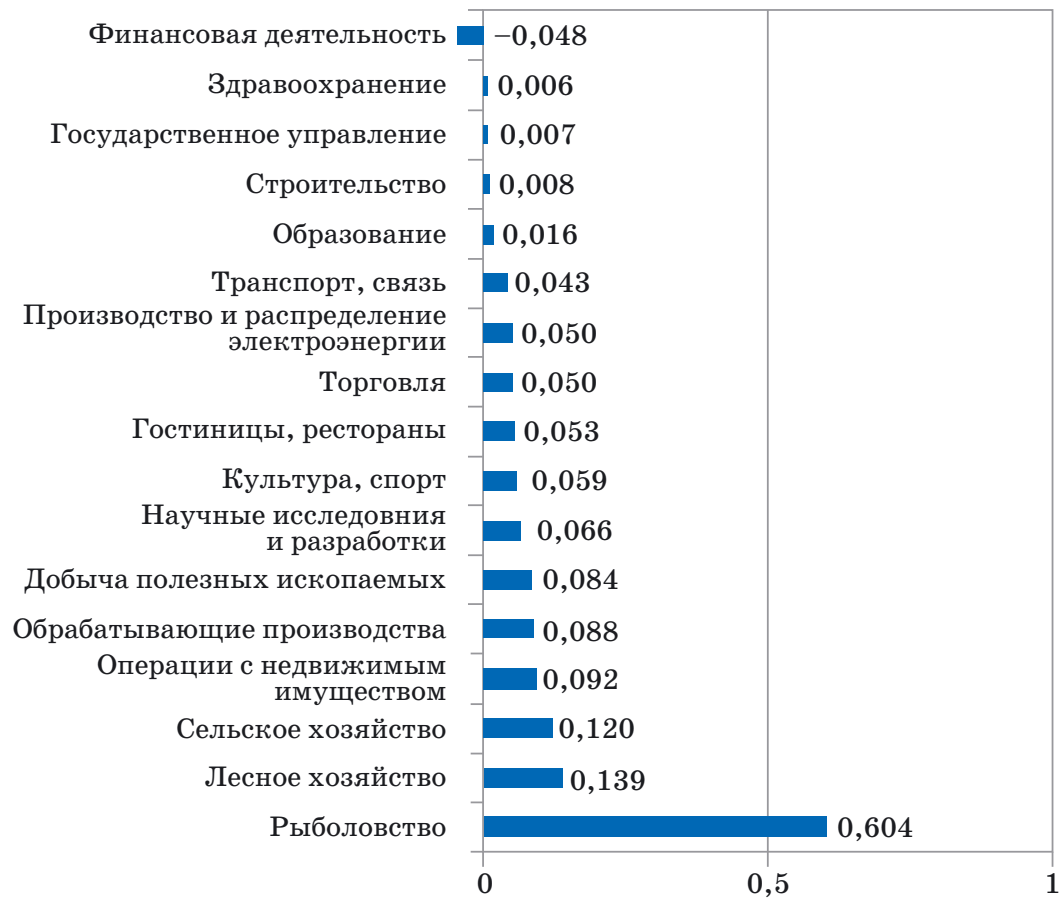

Рис. 3. Телпы прироста заработной платы работников Иркутской области по видам экономической деятельности за январь-октябрь 2015 2.

(Источник: Анализ заработной платы работников Иркутской области за январь-ноябрь 2015 года.

URL: http://irkzan.ru/home/ministerstvodeyatel/rinok/rinoktrudaanalizzp.aspx)

Как следствие, дисбаланс на рынке труда Иркутской области снижает демографические показатели, оказывающие значительное влияние на экономическое развитие региона, что существенно ухудшает совокупный инвестиционный потенциал области.

В настоящее время дисбаланс на рынке труда требует принятия соответствующих решений на федеральном уровне. Наиболее эффективными в этом случае могут быть следующие меры:

- ограничение проходных баллов для поступления на коммерческую форму обучения в образовательные организации высшего образования;

- расширение практики целевого приема на обучение;

- ограничение количества мест для коммерческой формы обучения в образовательных организациях высшего образования;

- поступление на коммерческую форму обучения в образовательные организации высшего образования только при наличии подписанного договора, обеспечивающего трудоустройство выпускника по окончании обучения;

- ограничение возможности при отчислении студента за неуспеваемость на поступление на коммерческую форму обучения на период до трех лет, с возможностью

${ }^{6}$ URL: http://irkzan.ru/home/ministerstvodeyatel/rinok/rinoktrudaanalizzp.aspx.

\section{Baikal Research Journal}


понижения этого срока после прохождения срочной службы в армии, рождения ребенка или при наличии подписанного договора, обеспечивающего трудоустройство выпускника по окончании обучения, параллельно с этим возможность обучения в образовательных организациях среднего профессионального образования должна быть сохранена;

- прямое ценовое регулирование оплаты за обучение по невостребованным экономикой направлениям подготовки;

- рассмотрение возможности предоставления выпускникам технических направлений подготовки образовательных организаций среднего профессионального образования, проработавшим три года по специальности, права получения высшего образования по аналогичному направлению подготовки на бюджетной основе без вступительных испытаний.

При реализации представленных мероприятий по снижению дисбаланса на региональном рынке труда также необходимо учитывать фактор инерционности, заключающийся в запаздывании, немгновенности реакции системы (объекта воздействия) на силу воздействия [12, с. 153]. Изменение экономической конъюнктуры, динамики спроса и предложения на рынке труда во времени всегда происходит с конечной скоростью, поэтому и причины, и следствия всегда растянуты во времени.

После прекращения действия причины, следствие может проявляться еще очень долго. В данном случае на рынке труда Иркутской области при введении в действии указанных решений инерционность будет проявляться в растянутости во времени получения сбалансированности спроса и предложения рабочей силы. Соответственно, развитие инвестиционных взаимосвязей можно представить как исчезновение старого и появление нового экономического пространства во времени, а времени в пространстве [13, с. 73]. Развитие инвестиционных процессов предполагает непостоянство, временный характер действия, их соответствие потребностям экономики в капиталовложениях, поэтому инерцию можно связать с несвоевременностью, преждевременностью появления одних форм инвестиционных взаимосвязей и с опозданием становления других.

Таким образом, инерционность экономических систем выражает соотношения явлений, т. е. указывает на единообразие связей между институтами. Данная безотносительность позволяет считать взаимодействие между институтами устойчивым во времени и порождающим действие свойств инерционности экономических систем. Формула экономического развития отождествляется с инвариантностью явлений и изменяется под воздействием государственного регулирования. Инерционность экономических систем предопределяет устойчивость развития, зависимую от изменения государственного потребления, а значит, выражает организацию и взаимодействие между институтами.

\section{Список использованной литературы}

1. Журавский M. Ю. Учет фактора инерционности в прогнозировании социально-экономического развития [Электронный ресурс] / М. Ю. Журавский, Ю. А. Журавский. - Режим доступа : http://pozdnyakov.tut.su/Seminar/art99/a011299.html.

2. Журавский М. Ю. К вопросу об инерционности развития инвестиционной формы отношений обновления основного капитала и ее регулировании в российской экономике / М. Ю. Журавский // Вестник Кузбасского государственного технического университета. 2005. — № 4.2 (49). - С. 87-91.

3. Долина О. Н. Инерционность пенсионной системы России, ее плюсы и минусы / О. Н. Долина // Аудит и финансовый анализ. - 2012. - № 2. - С. 310-313.

4. Бирюкова А. И. Оценка инвестиционной привлекательности промышленного сектора региона : автореф. дис. ... канд. экон. наук : 08.00.05 / А. И. Бирюкова. - Иркутск, 2004. -25 c.

\section{Baikal Research Journal}


5. Олейник А. Н. Институциональная экономика : учеб. пособие / А. Н. Олейник. - М. : Инфра-М, 2000. - 416 с.

6. Сиднина В. Л. Формы проявления инерционности в социально-экономической системе / В. Л. Сиднина // Вестник Оренбургского государственного университета. - 2002. № $2 .-$ C. $150-154$.

7. Павлов К. В. Инерционность социально-экономических систем / К. В. Павлов // Общество и экономика. - 2001. - № 10. - С. 59-67.

8. Дворядкина Е. Б. Инерционность как свойство экономического развития городов традиционно-промышленного региона / Е. Б. Дворядкина, Е. В. Голошейкин, И. В. Арагилян // Управленец. - 2014. - № 5 (51). - С. 72-78.

9. Озерникова Т. Г. Прогнозирование потребности региона в кадрах с профессиональным образованием / Т. Г. Озерникова, Д. В Марков / Современная конкуренция. — 2008. № 4 . - С. $105-115$.

10. Солодова Н. Г. Управление человеческими ресурсами в неустойчивых деловых организациях : автореф. дис. ... д-ра экон. наук : 08.00.05 / Н. Г. Солодова. - Иркутск, 2004. - 29 с.

11. Сакович Д. А. Эффекты спиралей как внутренняя основа инерционности рынка финансового капитала в условиях глобализации / Д. А. Сакович // Микроэкономика. 2010. - № 4. - С. 78-83.

12. Кибиткин А. И. Особенности инерционности как свойства социо-эколого-экономической системы предприятия промышленного рыболовства / А. И. Кибиткин, С. В. Петрова // Труды Карельского научного центра Российской академии наук. - 2012. — № 6. - С. $152-156$.

13. Сиднина В. Л. Инерционность экономической системы / В. Л. Сиднина // Общество и экономика. - 2002. - № 2. - С. 67-82.

\section{References}

1. Zhuravsky M. Yu. Zhuravsky Yu. A. Uchet faktora inertsionnosti v prognozirovanii sotsial'no-ekonomicheskogo razvitiya [Considering the inertia factor in forecasting socio-economic development. Available at http://pozdnyakov.tut.su/Seminar/art99/a011299.html. (In Russian).

2. Zhuravsky M. Yu. On issue of development inertia for investment form of relations in fixed assets replacement and its regulation in Russian economy. Vestnik Kuzbasskogo gosudarstvennogo tekhnicheskogo universiteta $=$ Bulletin of Kuzbass State Technical University, 2005, no. 4.2 (49), pp. 87-91. (In Russian).

3. Dolina O. N. Inertia of Russia's pension system, its pluses and minuses. Audit i finansovyi analiz $=$ Auditing and Financial Analysis, 2012, no. 2, pp. 310-313. (In Russian).

4. Biryukova A. I. Otsenka investitsionnoi privlekatel'nosti promyshlennogo sektora regiona. Avtoref. Kand. Diss. [Assessment of investment attractiveness of regional industrial sector. Cand. Diss. Thesis]. Irkutsk, 2004. 25 p.

5. Oleinik A. N. Institutsional'naya ekonomika [Institutional Economics]. Moscow, Infra-M Publ., 2000. 416 p.

6. Sidnina V. L. Forms of inertia manifestation in socio-economic system. Vestnik Orenburgskogo gosudarstvennogo universiteta $=$ Bulletin of Orenburg State University, 2002, no. 2, pp. 150-154. (In Russian).

7. Pavlov K. V. Inertia of socio-economic systems Obshchestvo $i$ ekonomika = Society and Economy, 2001, no. 10, pp. 59-67. (In Russian).

8. Dvoryadkina E. B. Golosheyikin E. V., Aragilyan I. V. Inertia as a property of economic development of cities in a traditional industrial region. Upravlenets $=$ The Manager, 2014, no. 5 (51), pp. 72-78. (In Russian).

9. Ozernikova T. G., Markov D. V. Forecasting of regional needs for personnel with professional education. Sovremennaya konkurentsiya = Modern competition, 2008, no. 4, pp. 105-115. (In Russian).

10. Solodova N. G. Upravlenie chelovecheskimi resursami $v$ neustoichivykh delovykh organizatsiyakh. Avtoref. Kand. Diss. [Management of human resources and unsustainable business organizations. Cand. Diss. Thesis]. Irkutsk, 2004. 29 p.

11. Sakovich D. A. Effects of spirals as an internal framework of inertia of financial capital market in terms of globalization. Mikroekonomika $=$ Microeconomics, 2010, no. 4, pp. $78-83$. (In Russian).

\section{Baikal Research Journal}


12. Kibitkin A. I., Petrova S. V. Some characteristics of inertia as a feature of the socio-ecological economic system of a fishing company. Trudy Karel'skogo nauchnogo tsentra Rossiiskoi akademii nauk = Transactions of Karelian Research Centre of the Russian Academy of Sciences, 2012, no. 6, pp. 152-156. (In Russian).

13. Sidnina V. L. Inertia of economic system. Obshchestvo i ekonomika = Society and Econo$m y, 2002$, no. 2, pp. 67-82. (In Russian).

\section{Информация об авторе}

Новикова Ирина Юрьевна - аспирант, кафедра экономики и управления бизнесом, Байкальский государственный университет, 664003, г. Иркутск, ул. Ленина, 11, e-mail: arinkachka18@mail.ru.

\section{Author}

Irina Yu. Novikova - PhD Student, Chair of Economics and Business Management, Baikal State University, 11 Lenin St., 664003, Irkutsk, Russian Federation; e-mail: arinkachka18@mail.ru.

\section{Библиографическое описание статьи}

Новикова И. Ю. Анализ кадрового потенциала Иркутской области и особенности проявления инерционности на региональном рынке труда / И. Ю. Новикова // Baikal Research Journal. - 2016. — T. 7, № 2. - DOI : 10.17150/2411-6262.2016.7(2).18.

\section{Reference to article}

Novikova I. Yu. Analysis of personnel potential of Irkutsk Oblast and features of inertia manifestation on the regional labor market. Baikal Research Journal, 2016, vol. 7, no. 2. DOI: 10.17150/2411-6262.2016.7(2).18. (In Russian).

\section{Baikal Research Journal}

